\title{
Clinical presentation of Lyme disease in the higher-risk region of Quebec: a retrospective descriptive study
}

\author{
Audrey Charbonneau MD, Louis-Philippe Charette MD, Geneviève Rouleau MD, Mélissa Savary MD, \\ Alexandra Wilson MD, Emily Heer BSc, Karine Bériault MD, Alexandra de Pokomandy MDCM MSc
}

\section{Abstract}

Background: Lyme disease is emerging in Canada. This study aimed to describe the use of serologic testing for the disease in the La Pommeraie health region in southern Quebec between 2012 and 2015 and to describe the clinical presentation of laboratoryconfirmed cases.

Methods: The medical charts of all patients investigated for Lyme disease at the Brome-Missisquoi-Perkins Hospital's laboratory between 2012 and 2015 were reviewed for results of serologic testing. Laboratory diagnosis was based on 2-tiered testing: cases had to have positive results of both the enzyme immunoassay and the Western blot test (IgM or IgG). We collected data on clinical presentation for patients assessed at the hospital or at the La Pommeraie Family Medicine Unit.

Results: Over the study period, 720 patients were investigated for Lyme disease. There was a more than fivefold increase in requests for serologic testing from 2012 (53) to 2015 (273). The number of confirmed cases increased from 2012 (3) to 2013 (19) and remained stable thereafter (19 in 2014, 18 in 2015). Fifty patients were positive for IgM with or without IgG positivity, and 9 patients were IgG-positive only. Chart reviews were completed for 278 of the 720 patients, including 38 of the 59 laboratoryconfirmed cases. Among the 29 IgM-positive patients, the most common symptoms were fever (17 patients [59\%]), fatigue (14 [48\%]), myalgia (12 [41\%]) and headaches (10 [34\%]). Twenty-three (79\%) had some cutaneous manifestation, including specifically erythema migrans (14 [48\%]). A tick bite was reported by 11 patients $(38 \%)$. Of the 44 patients in the entire study population who presented with erythema migrans, 15 (34\%) had confirmed Lyme disease.

Interpretation: Requests for serologic testing for Lyme disease increased in the La Pommeraie health region over recent years. Cutaneous manifestations, fever and myalgia were the most common symptoms of IgM-positive cases. Most patients did not report a tick bite.

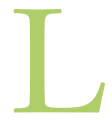

yme disease is emerging in Canada. ${ }^{1-3}$ In Quebec, 160 cases were reported in 2015, compared to only 2 cases in 2004., ${ }^{4,5}$ This disease is caused by the spirochete Borrelia burgdorferi, which is present in the saliva of infected ticks. ${ }^{5}$ Untreated, the infection can affect multiple organs and systems, including the skin, heart, eyes, central and peripheral nervous system, and musculoskeletal system. ${ }^{5}$ Quebec guidelines recommend serologic testing for Lyme disease in the presence of erythema migrans or any symptom suggestive of Lyme disease, even without an observed tick bite. ${ }^{6}$ Symptoms include fatigue, headache, anorexia, fever, regional lymphadenopathy, myalgia and diffuse arthralgia. ${ }^{6}$ These are nonspecific ailments frequently encountered in primary care. It is therefore challenging for primary caregivers or emergency physicians to properly detect Lyme disease cases.

Considering the serious consequences of this disease and its increasing prevalence, medical residents from the La Pommeraie Family Medicine Unit (Université de Sherbrooke) designed a research project to inform clinicians on the presentation of confirmed cases and to help case detection of Lyme disease. The first objective of this study was to review the use of requests for serologic testing sent to the Brome-Missisquoi-
Perkins Hospital microbiology laboratory between 2012 and 2015 and the proportion of positive results. The second objective was to describe the most commonly reported clinical presentations of laboratory-confirmed cases and to examine the proportion of confirmed diagnoses in people presenting with erythema migrans and investigated for Lyme disease.

\section{Methods}

\section{Setting}

In an analysis by the Institut national de santé publique du Québec on the of level of risk of Lyme disease in Quebec municipalities, the only high-risk municipality was Farnham, in the Eastern Townships, where more than $20 \%$ of ticks were

\section{Competing interests: None declared.}

This article has been peer reviewed.

Correspondence to: Alexandra de Pokomandy, alexandra. depokomandy@mcgill.ca

CMAJ Open 2018. DOI:10.9778/cmajo.20170084 
infected with $B$. burgdorferi. ${ }^{7}$ This municipality as well as 5 of the 20 considered at moderate risk (Brigham, Bromont, Cowansville, Saint-Armand and Sutton ${ }^{7}$ ) are served by the Brome-Missisquoi-Perkins Hospital, a primary care hospital in Cowansville offering outpatient and inpatient health care services, with 84 short-term care beds and 12 long-term care beds. It is part of the Centre intégré universitaire de santé et de services sociaux de l'Estrie - Centre hospitalier universitaire de Sherbrooke and provides medical services for the population living in the La Pommeraie local health and social service network (22 municipalities: Abercorn, Frelighsburg, SaintArmand, Pike River, Stanbridge Station, Bedford Township, Stanbridge East, Dunham, Sutton, West Bolton, Brome, Brome Lake, Cowansville, East Farnham, Brigham, SaintIgnace-de-Stanbridge, Notre-Dame-de-Stanbridge, SainteSabine, Farnham, Ange-Gardien and Sainte-Brigided'Iberville) (Figure 1). During the study period, it also provided services for Bromont and Waterloo. Requests for serologic testing for Lyme disease ordered by a physician working in this hospital or at one of the 14 medical clinics in the local network are first sent to the microbiology laboratory of the BromeMissisquoi-Perkins Hospital. In Quebec, laboratory diagnosis of Lyme disease is made through 2-tiered testing, as recommended by the Centers for Disease Control and Prevention. ${ }^{8}$ Specimens are first tested in regional laboratories through enzyme immunoassay, and only specimens with positive results are sent for further analysis to the National Microbiology Laboratory, Winnipeg, where the enzyme immunoassay is repeated and positive results are processed to complete Western blot testing for $\operatorname{IgM}$ and IgG. ${ }^{6}$ We began our data collection in 2012 because only 28 cases of Lyme disease were reported in Quebec in 2011, and the rising incidence began thereafter. ${ }^{4}$

\section{Design}

The study was a retrospective descriptive study based on chart review. For the first objective, we included all patients for whom serologic testing for Lyme disease had been requested at the microbiology laboratory of the Brome-Missisquoi-
Perkins Hospital between Jan. 1, 2012, and Dec. 31, 2015, as provided by the microbiology laboratory of the hospital. We conducted electronic chart reviews to collect sex, age at testing, postal code of residence and serologic testing results from both the regional laboratory and the National Microbiology Laboratory. Serology regional laboratories varied frequently, and the name of the kits used were often not available. Serology assays used in regional laboratories varied frequently, and the name of the kits used were often not available. At the National Microbiology Laboratory, the Immunetics C6 Lyme ELISA Kit was used for the enzyme immunoassay, and the Euroimmun Western blot assay was used for IgM and IgG testing.

For the second objective, we included the same study population as for objective 1 and excluded all patients whose medical charts at the Brome-Missisquoi-Perkins Hospital or the La Pommeraie Family Medicine Unit did not contain information related to a request for serologic testing for Lyme disease or were unreadable. The medical charts of patients assessed in other outpatient medical clinics of the La Pommeraie local health network were not accessible by our research team. Medical charts were reviewed by 5 of the authors (A.C., L.-P.C., G.R., M.S. and A.W.) using a paper case report form created and piloted at the beginning of the study to standardize data collection between researchers. The form required simple box ticking (yes/no or multiple choice) or date entry. Minimal text entry was possible when "other" was selected. The information collected included specific risk factors (history of travel or tick bite), systemic signs and symptoms reported (fever, fatigue, headache, anorexia, lymphadenopathy, malaise, lethargy, alteration in level of consciousness), skin manifestations (erythema migrans, other cutaneous lesion), musculoskeletal symptoms (myalgia, arthralgia, migratory pains, arthritis, other), neurologic signs or symptoms (nuchal rigidity, facial paralysis, meningitis, encephalitis, polyradiculopathy, other), cardiac manifestations (atrioventricular block, myocarditis, pericarditis, other) and ophthalmic manifestations (conjunctivitis, keratitis, uveitis, optic neuritis, other). Case report forms were scanned with TeleForm software, and all data recorded

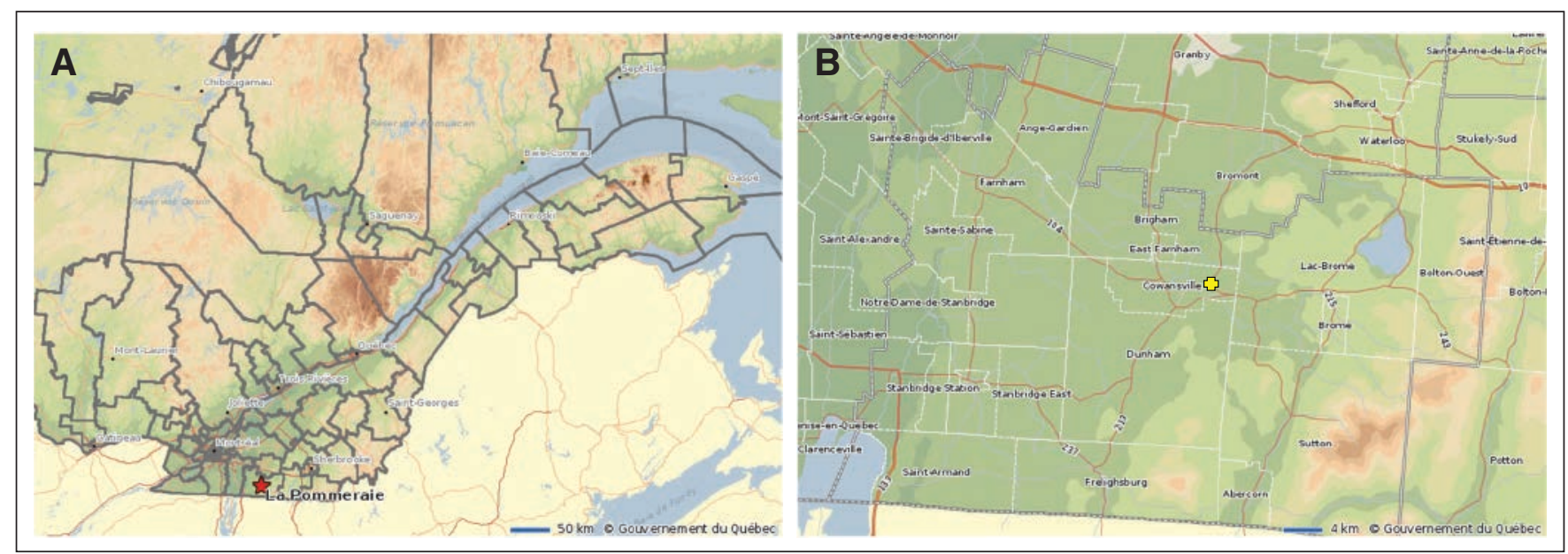

Figure 1: (A): Location of La Pommeraie local health and social service network in Quebec. (B): Location of municipalities within La Pommeraie network. Yellow cross indicates location of Brome-Missisquoi-Perkins Hospital. Source: ministère de la Santé et des Services sociaux du Québec (www.msss.gouv.qc.ca/statistiques/atlas/atlas/index.php). Reproduced with permission. 
were then reviewed by a research assistant to verify concordance with the paper forms.

\section{Statistical analysis}

We calculated descriptive analyses with $95 \%$ confidence intervals (CIs) to answer the study objectives. To identify cases, we considered only the results of the confirmatory IgM and IgG serologic tests performed at the National Microbiology Laboratory on samples with positive or equivocal results of the enzyme immunoassay. For patients for whom more than 1 serologic test was completed, we retained the first positive IgM test result. For patients not positive for IgM, we retained the first positive IgG test result or, if all tests gave a negative result, the first test result. Signs and symptoms from the chart review were categorized as "no" if they were not mentioned in the medical note. Statistical analyses were performed with Stata software, version 11.2 (StataCorp).

\section{Ethics approval}

Ethics approval was provided by the research ethics board of the Centre de recherche du Centre hospitalier universitaire de Sherbrooke.

\section{Results}

Of the 720 people investigated for Lyme disease at the Brome-Missisquoi-Perkins Hospital laboratory between Jan. 1, 2012, and Dec. 31, 2015, 3 were excluded because their results were unavailable. Of the remaining 717 patients, 50 were positive for $\operatorname{IgM}$ (of whom 25 were $\operatorname{IgG}$-negative, 17 were IgG-positive, and 8 had equivocal results for $\operatorname{IgG}$ ), and 9 were positive for IgG only (Figure 2). Table 1 presents demographic characteristics of all 59 patients with laboratoryconfirmed Lyme disease and the subgroup of IgM-positive patients. Of the 59 patients, over two-thirds (40 [68\%,

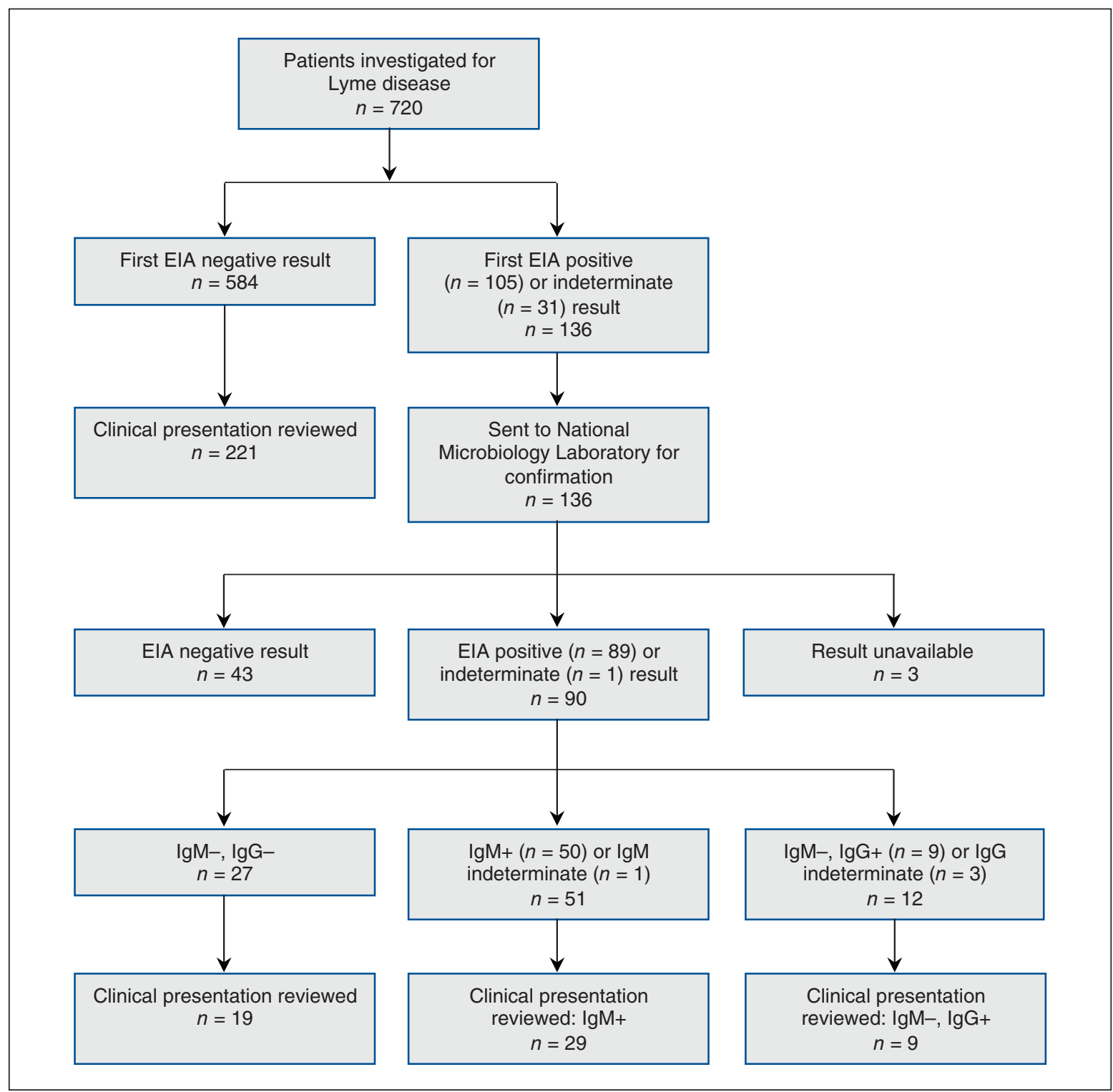

Figure 2: Flow diagram showing identification of study cases. Note: EIA = enzyme immunoassay. 


\begin{tabular}{|c|c|c|}
\hline \multicolumn{3}{|c|}{$\begin{array}{l}\text { Table 1: Characteristics of patients with Lyme disease } \\
\text { confirmed by laboratory diagnosis through 2-tiered testing, } \\
2012 \text { and } 2015\end{array}$} \\
\hline \multirow[b]{2}{*}{ Characteristic } & \multicolumn{2}{|c|}{ No. (\%) of patients } \\
\hline & $\begin{array}{l}\text { IgM-positive or } \\
\text { IgG-positive } \\
n=59\end{array}$ & $\begin{array}{c}\text { IgM-positive } \\
n=50\end{array}$ \\
\hline \multicolumn{3}{|l|}{ Age, yr } \\
\hline$\leq 19$ & $7(12)$ & $5(10)$ \\
\hline 20-39 & $21(36)$ & $18(36)$ \\
\hline $40-59$ & $17(29)$ & $14(28)$ \\
\hline$\geq 60$ & $14(24)$ & $13(26)$ \\
\hline Male sex & $40(68)$ & $3468)$ \\
\hline \multicolumn{3}{|c|}{ Area of residence } \\
\hline Brome Lake & $11(19)$ & $9(18)$ \\
\hline Bedford & $8(14)$ & $8(16)$ \\
\hline Cowansville & $16(27)$ & $12(24)$ \\
\hline Bromont & $19(32)$ & $18(36)$ \\
\hline Farnham & $2(3)$ & $1(2)$ \\
\hline Other & $3(5)$ & $2(4)$ \\
\hline \multicolumn{3}{|c|}{ Year of serologic testing } \\
\hline 2012 & $3(5)$ & $2(4)$ \\
\hline 2013 & $19(32)$ & $18(36)$ \\
\hline 2014 & $19(32)$ & $17(34)$ \\
\hline 2015 & $18(30)$ & $13(26)$ \\
\hline
\end{tabular}

95\% CI 54.4\%-79.4\%]) were men, and most were aged 20-39 years $(21[36 \%, 95 \%$ CI $23.6 \%-49.1 \%])$ or $40-$ 59 years (17 [29\%, 95\% CI 17.8\%-42.1\%]). Over half lived in Cowansville (16 [27\%, 95\% CI 16.4\%-40.3\%]) or Bromont (19 [32\%, 95\% CI 20.6\%-45.6\%]).

Over the study period, the annual number of requests for serologic testing for Lyme disease increased more than fivefold, from 53 in 2012 to 273 in 2015 (Figure 3). The proportion of local tests with positive results also increased, but the number of cases confirmed at the National Microbiology Laboratory increased only from 2012 (3 cases) to 2013 and remained stable at around 18-19 cases per year from 2013 to 2015. Considerably more requests and laboratory diagnoses were made between June and October, particularly in July (Figure 3).

\section{Clinical presentation of patients with positive test results}

Medical chart reviews were completed for 38 of the 59 laboratory-confirmed cases: 29 patients were IgM-positive, and 9 were IgM-negative and IgG-positive. All 38 patients were investigated in an outpatient context, 22 in the emergency department and 16 at outpatient clinics.

Signs and symptoms reported for the 38 patients with confirmed Lyme disease are presented in Table 2. Fever
(20 patients [53\%, 95\% CI 35.8\%-69.0\%]), fatigue (18 [47\%, 95\% CI 31.0\%-64.2\%]), myalgia (15 [39\%, 95\% CI $24.0 \%-$ $56.6 \%])$ and headaches (12 [32\%, 95\% CI 17.5\%-48.6\%]) were the most commonly reported symptoms. Cutaneous manifestations were present in 27 patients $(71 \%, 95 \% \mathrm{CI}$ $54.1 \%-84.6 \%)$ and in $23(79 \%, 95 \%$ CI $60.3 \%-92.0 \%)$ of the 29 IgM-positive patients. Erythema migrans was specifically reported in 15 patients $(39 \%, 95 \%$ CI $24.0 \%-56.6 \%)$; it was reported in $14(48 \%, 95 \%$ CI $29.4 \%-67.5 \%)$ of the patients positive for IgM. Four patients (10\%, 95\% CI $2.9 \%-$ $24.8 \%$ ) presented with facial paralysis; otherwise, neurologic, cardiac and ophthalmic presentations were rare. A tick bite was reported by 12 patients (32\%, 95\% CI $17.5 \%-48.6 \%$ ) overall and 11 (38\%, 95\% CI $20.7 \%-57.7 \%)$ of the IgMpositive patients.

Of the 278 patients investigated for Lyme disease whose medical chart could be reviewed, 44 (16\%, 95\% CI $11.7 \%-$ $20.7 \%$ ) presented with erythema migrans. Of the 44,14 (32\%, 95\% CI 18.6\%-47.6\%) were IgM-positive, 1 (2\%, $95 \%$ CI $0.1 \%-12.0 \%$ ) was positive only for $\operatorname{IgG}$, and 29 $(66 \%, 95 \%$ CI $50.1 \%-79.5 \%)$ had a negative result of the enzyme immunoassay or were negative for both IgM and IgG.

\section{Interpretation}

We identified a steep rise in requests for serologic testing for Lyme disease at the Brome-Missisquoi-Perkins Hospital between 2012 and 2015 but a relatively stable number of cases per year (18-19) from 2013 to 2015. Confirmed cases were most common in men aged 20-59 years living in Cowansville or Bromont. Only 32\% reported a tick bite. The most common symptoms reported for confirmed cases were fever, fatigue, myalgia and headaches. Cutaneous findings were present in $71 \%$, but erythema migrans was specifically identified in only $39 \%$ of patients overall and $48 \%$ of IgM-positive patients.

The increase in the number of Lyme disease cases in the La Pommeraie health region is consistent with the migration of ticks from the northeast United States to Canada. ${ }^{9}$ Although a 2016 study identified Farnham as the sole high-risk municipality in the province, ${ }^{7}$ only 2 laboratory-confirmed cases were from that municipality during the study period. It is possible that people living in Farnham had their laboratory testing done in other regions. Furthermore, our data do not include patients in whom a clinical diagnosis was made based on erythema migrans, for whom serologic testing may not have been requested. Lyme disease can be diagnosed clinically without serologic testing in patients with a history of exposure to ticks who present in season with typical erythema migrans of at least $5 \mathrm{~cm}$; in such cases, antibiotic treatment should be given irrespective of serologic results. ${ }^{10-13}$ However, the 2013 Quebec guidelines recommend serologic testing in the presence of any signs or symptoms compatible with Lyme disease. ${ }^{6}$ The high number of cases identified in Bromont and Cowansville should raise concern that people living in those areas are at high risk, whether this is due to the presence of ticks in their residential areas or to greater exposure to ticks through a higher prevalence of outdoor activities in wooded areas. Tick bites were 
A

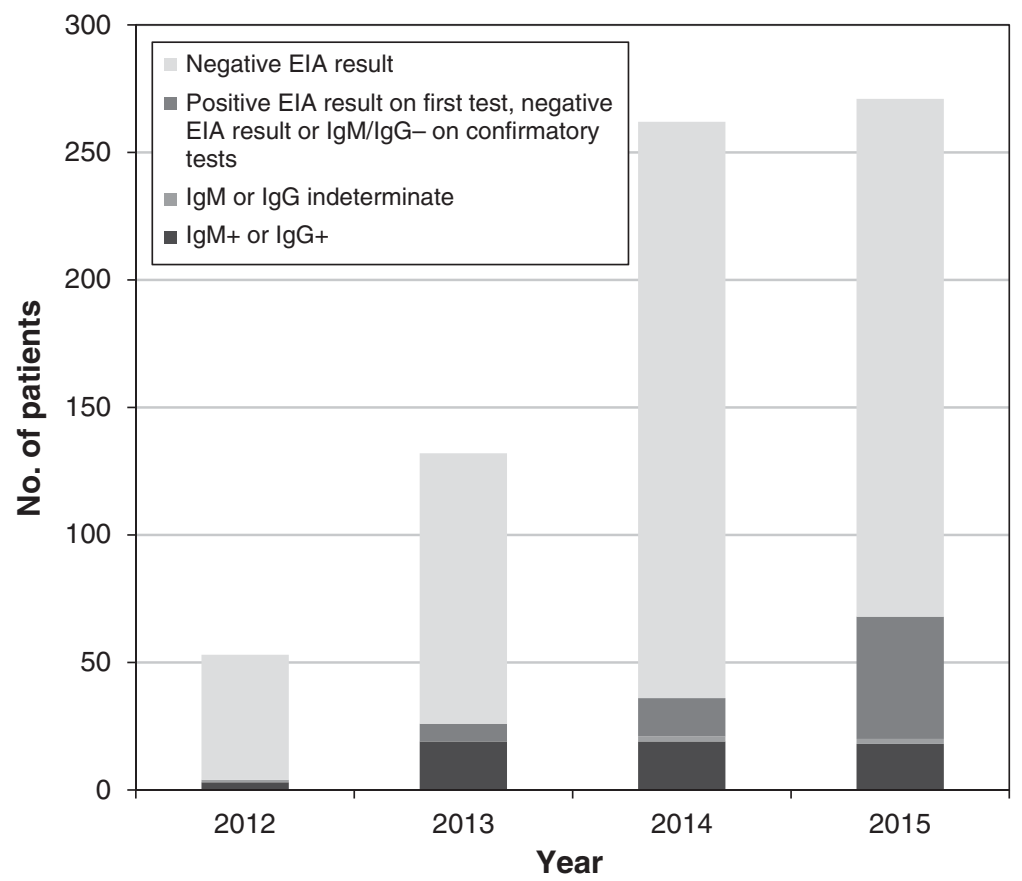

B

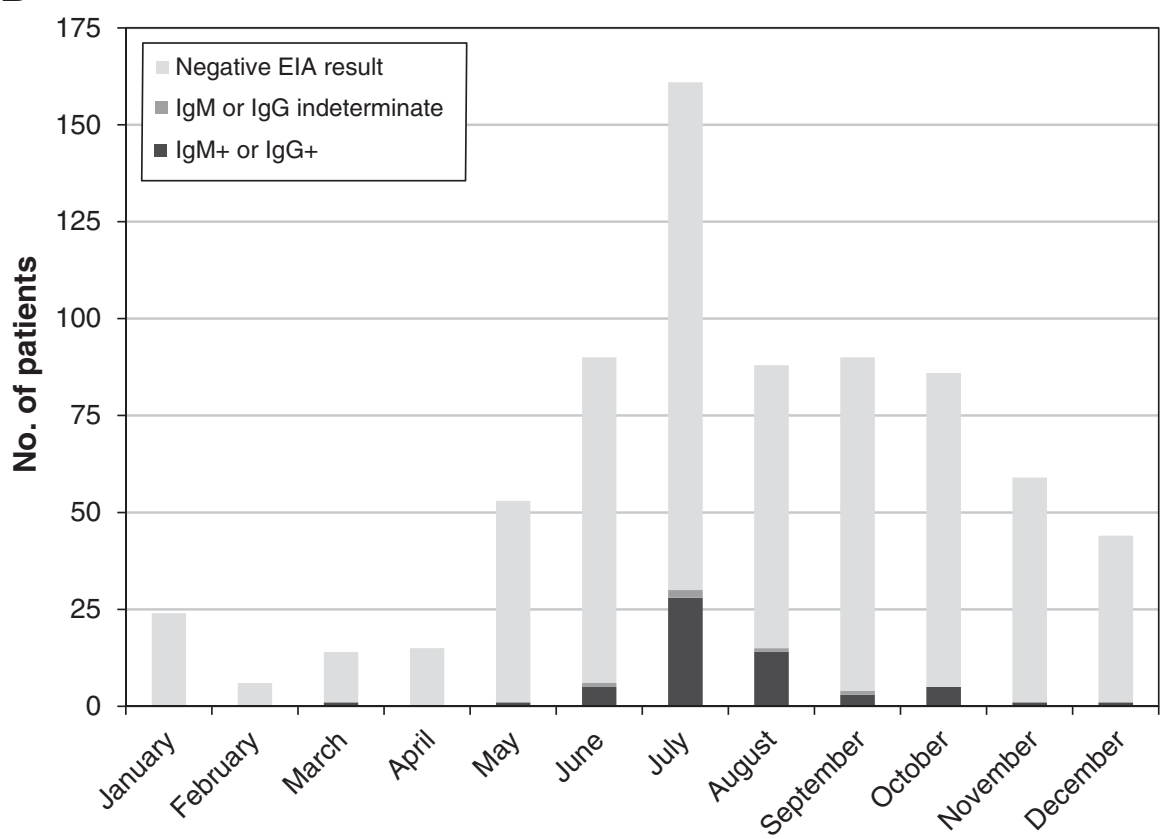

Figure 3: Absolute number of patients for whom a request for serologic testing for Lyme disease was sent to the BromeMissisquoi-Perkins Hospital, by year (A) and month (all years combined) (B). Note: EIA = enzyme immunoassay.

reported by only $32 \%$ of patients in our cohort, which is consistent with previous reports. ${ }^{6}$

Because the most commonly reported symptoms are not specific to Lyme disease, properly diagnosing Lyme disease is challenging. In our study population, cutaneous manifestations were common, although in many cases they were not described specifically as erythema migrans but, rather, as rash or cellulitis. Misclassification is possible, as in some cases the undefined rash or cellulitis may have been erythema migrans, and it was not possible on retrospective chart review to verify whether the erythema migrans was properly diagnosed. A recent publication suggested that physicians in 


\begin{tabular}{|c|c|c|}
\hline \multirow[b]{2}{*}{ Characteristic } & \multicolumn{2}{|c|}{ No. (\%) of patients } \\
\hline & $\begin{array}{l}\text { IgM-positive or } \\
\text { IgG-positive } \\
n=38\end{array}$ & $\begin{array}{l}\text { IgM-positive } \\
\quad n=29\end{array}$ \\
\hline \multicolumn{3}{|l|}{ Sign/symptom } \\
\hline \multicolumn{3}{|l|}{ Systemic } \\
\hline Any & $30(79)$ & $25(86)$ \\
\hline $\begin{array}{l}\text { Fever (reported or } \\
\text { objective) }\end{array}$ & $20(53)$ & $17(59)$ \\
\hline Fatigue & $18(47)$ & $14(48)$ \\
\hline Headaches & $12(32)$ & $10(34)$ \\
\hline Anorexia & $5(13)$ & $5(17)$ \\
\hline Lymphadenopathy & $3(8)$ & $3(10)$ \\
\hline Malaise & $9(24)$ & $7(24)$ \\
\hline Lethargy & $2(5)$ & $1(3)$ \\
\hline \multicolumn{3}{|l|}{ Cutaneous } \\
\hline Any & $27(71)$ & $23(79)$ \\
\hline Erythema migrans & $15(39)$ & $14(48)$ \\
\hline Cellulitis & $2(5)$ & $2(7)$ \\
\hline Other & $10(26)$ & $7(24)$ \\
\hline \multicolumn{3}{|l|}{ Musculoskeletal } \\
\hline Any & $20(53)$ & $13(45)$ \\
\hline Myalgia & $15(39)$ & $12(41)$ \\
\hline Arthralgia & $7(18)$ & $4(14)$ \\
\hline Migratory pains & $3(8)$ & $3(10)$ \\
\hline Arthritis & $4(10)$ & $1(3)$ \\
\hline \multicolumn{3}{|l|}{ Neurological } \\
\hline Any & $7(18)$ & $5(17)$ \\
\hline Nuchal rigidity & $2(5)$ & $1(3)$ \\
\hline Facial paralysis & $4(10)$ & $3(10)$ \\
\hline Polyradiculopathy & $1(3)$ & $1(3)$ \\
\hline \multicolumn{3}{|l|}{ Cardiac } \\
\hline Any & $2(5)$ & $2(7)$ \\
\hline Atrioventricular block & $2(5)$ & $2(7)$ \\
\hline \multicolumn{3}{|l|}{ Ophthalmic } \\
\hline Any & $1(3)$ & $1(3)$ \\
\hline Conjunctivitis & $1(3)$ & $1(3)$ \\
\hline \multicolumn{3}{|l|}{ History } \\
\hline $\begin{array}{l}\text { Reported travel in New } \\
\text { England }\end{array}$ & $3(8)$ & $3(10)$ \\
\hline Tick bite reported* & $12(32)$ & $11(38)$ \\
\hline
\end{tabular}

Quebec may have misdiagnosed erythema migrans in 63\% of patients. ${ }^{14}$ Our findings confirm that fever, fatigue, myalgia and cutaneous presentations remain the most likely presen- tation of Lyme disease. Although only 4 patients in our cohort presented with facial paralysis, a recent report from England suggested that the combination of Bell's palsy with Lyme disease is increasing, and the authors recommended that physicians bear Lyme disease in mind when seeing patients with facial palsy. ${ }^{15}$

\section{Limitations}

The main limitation of this study is the potential information bias due to the retrospective design, as well as selection bias since the medical records were limited to those of the hospital or the La Pommeraie Family Medicine Unit. It is possible that patients who presented with the classic clinical features of erythema migrans, fever and history of tick bites were most likely to be managed entirely outside the hospital and that more atypical presentations were most likely to be referred to the hospital for specialist opinion. We could also not assess pet ownership as a previously reported risk factor. ${ }^{16,17}$ In addition, the tests currently used to diagnose Lyme disease are imperfect. The enzyme immunoassay is very sensitive and is used first to ensure that true cases of Lyme disease are not missed. However, false-positive results may occur, especially in the context of other diseases such as tickborne relapsing fever, syphilis, bacterial endocarditis, certain autoimmune disorders (e.g., lupus) and other infections, which is why all samples with positive results require subsequent Western blot testing. ${ }^{8}$ The latter detects antibodies to B. burgdorferi but has its pitfalls and should be performed only on samples with positive or equivocal results of the enzyme immunoassay. IgM positivity suggests acute Lyme disease but is meaningful only during the first 30 days of illness; to avoid a possible false-positive result, Western blot testing for IgM should not be performed if symptoms have been present for more than 30 days. IgG antibodies appear only after 4-6 weeks of illness and may persist for years, which also means they may not be related to the symptoms under investigation. ${ }^{8}$ The predictive value of the enzyme immunoassay and the Western blot test relies on the pretest probability in the population tested and should be used only in patients with symptoms suggestive of or possible exposure to Lyme disease. Although the National Microbiology Laboratory generally only tests for IgG (and not IgM) if the requisition indicates that symptoms have been present for more than 30 days, we had no means to verify how often the onset of symptoms was indicated on the requisitions, and our retrospective study design did not allow us to properly measure the duration of symptoms at the time of testing. Falsepositive results among the IgM-positive cases are thus possible. False-negative results are also possible if patients were tested too early after the onset of symptoms and were not retested 2-4 weeks later. The fact that we used only 1 test result per person may have led to loss of information. Since most of the patients in our cohort were IgM-positive, we could not identify striking differences between acute and later presentations. Finally, the generalizability of our results for other areas in Canada may be limited, as the prevalence of Lyme disease varies considerably by region. 


\section{Conclusion}

The rising incidence of Lyme disease in Canada is an important public health concern. Data from areas with higher prevalence may guide primary care physicians to properly include Lyme disease in their differential diagnosis and to use serologic testing for the disease optimally. Unfortunately, serologic testing remains an imperfect method to diagnose Lyme disease. When serologic testing is done, 2-tier testing should always be used to establish a laboratory-confirmed diagnosis, and testing should be performed only in people with symptoms suggestive of or possible exposure to Lyme disease. Attention to the onset of symptoms in interpreting results is important until better diagnostic tests are available.

\section{References}

1. Ogden NH, Lindsay LR, Morshed M, et al. The emergence of Lyme disease in Canada. CMA7 2009;180:1221-4.

2. Gasmi S, Ogden NH, Leighton PA, et al. Analysis of the human population bitten by Ixodes scapularis ticks in Quebec, Canada: increasing risk of Lyme disease. Ticks Tick Borne Dis 2016;7:1075-81.

3. Ogden NH, Feil EJ, Leighton PA, et al. Evolutionary aspects of emerging Lyme disease in Canada. Appl Environ Microbiol 2015;81:7350-9.

4. Adam-Poupart A, Thivierge A, Milord F. Rapport de surveillance de la maladie de Lyme : année 2015. Québec: Institut national de santé publique du Québec; 2016.

5. Ferrouillet C, Fortin A, Milord F, et al. Proposition d'un programme pour la surveillance intégrée de la maladie de Lyme et des autres maladies transmises par la tique Ixodes scapularis au Québec. Québec: Institut national de santé publique du Québec; 2014.

6. Lambert L, Drapeau M, Milord F, et al. Guide d'intervention : la maladie de Lyme. Québec: ministère de la Santé et des Services sociaux du Québec; 2013.

7. Adam-Poupart A, Milord F, Thivierge K. Proposition d'un programme pour la surveillance intégrée de la maladie de Lyme et des autres maladies transmises par la tique Ixodes scapularis au Québec : mise à jour 2015. Québec: Institut national de santé publique du Québec; 2016.

8. Two-step laboratory testing process. Atlanta: Centers for Disease Control and Prevention; 2015 [updated 2015 Mar. 26]. Available: https://www.cdc.gov/ lyme/diagnosistesting/labtest/twostep/index.html (accessed 2017 Nov. 16).

9. Simon JA, Marrotte RR, Desrosiers N, et al. Climate change and habitat fragmentation drive the occurrence of Borrelia burgdorferi, the agent of Lyme disease, at the northeastern limit of its distribution. Evol Appl 2014;7:750-64.

10. Lindsay LR, Bernat K, Dibernardo A. Laboratory diagnostics for Lyme disease. Can Commun Dis Rep 2014;40-11.
11. Canadian Public Health Laboratory Network. The laboratory diagnosis of Lyme borreliosis: guidelines from the Canadian Public Health Laboratory Network. Can 7 Infect Dis Med Microbiol 2007;18:145-8.

12. Wormser GP, Dattwyler RJ, Shapiro ED, et al. The clinical assessment, treatment, and prevention of Lyme disease, human granulocytic anaplasmosis, and babesiosis: clinical practice guidelines by the Infectious Diseases Society of America. Clin Infect Dis 2006;43:1089-134.

13. Lyme disease (Borrelia burgdorferi): 2017 case definition. Atlanta: Centers for Disease Control and Prevention; 2017. Available: https://wwwn.cdc.gov/nndss/ conditions/lyme-disease/case-definition/2017/ (accessed 2017 June 21).

14. Gasmi S, Ogden NH, Leighton PA, et al. Practices of Lyme disease diagnosis and treatment by general practitioners in Quebec, 2008-2015. BMC Fam Pract 2017;18:65.

15. Cooper L, Branagan-Harris M, Tuson R, et al. Lyme disease and Bell's palsy: an epidemiological study of diagnosis and risk in England. Br 7 Gen Pract 2017; 67:e329-35.

16. Jones EH, Hinckley AF, Hook SA, et al. Pet ownership increases human risk of encountering ticks. Zoonoses Public Health 2018;65:74-9.

17. Bouchard C, Leonard E, Koffi JK, et al. The increasing risk of Lyme disease in Canada. Can Vet 7 2015;56:693-9.

Affiliations: La Pommeraie Family Medicine Unit (Cowansville) (Charbonneau, Charette, Rouleau, Savary, Wilson, Bériault, de Pokomandy), Department of Family Medicine, Université de Sherbrooke, Sherbrooke, Que.; Departments of Public Health (Heer) and Family Medicine (de Pokomandy), McGill University, Montréal, Que.

Contributors: Audrey Charbonneau, Louis-Philippe Charette, Geneviève Rouleau, Mélissa Savary, Alexandra Wilson and Alexandra de Pokomandy conceived and designed the study and acquired the data. All of the authors contributed to data analysis and interpretation, drafted the manuscript, revised it critically for important intellectual content, gave final approval of the version to be published and agreed to be accountable for all aspects of the work.

Funding: Alexandra de Pokomandy received salary support from the Fonds de Recherche du Québec - Santé and the Fédération des médecins omnipraticiens du Québec through an LE-250 scholarship.

Acknowledgements: The authors thank Sophie Michaud, infectious diseases specialist at Brome-Missisquoi-Perkins Hospital, for her support and collaboration in this project, and Christina de Castro at the McGill University Health Centre for her assistance with data collection and study management.

Supplemental information: For reviewer comments and the original submission of this manuscript, please see www.cmajopen.ca/content/6/1/ E139/suppl/DC1. 